\title{
Serum immunoreactive relaxin in women during a 24-h period
}

\author{
K. Seki, K. Kato and T. Tabei* \\ Department of Obstetrics and Gynecology, National Defense Medical College, Tokorozawa, \\ Saitama 359, Japan and *Sekishindo Hospital, Kawagoe, Saitama 350, Japan
}

\begin{abstract}
Summary. Serum relaxin concentrations were measured every $30 \mathrm{~min}$ during a $24-\mathrm{h}$ period in nonpregnant and pregnant women. Relaxin was undetectable in all serum samples obtained from 3 nonpregnant women. Relaxin was detectable in all serum samples obtained from 2 pregnant women. However, neither episodic secretion of relaxin nor a 24 -h rhythm in relaxin secretion was discernible in these women.
\end{abstract}

\section{Introduction}

Bryant et al. (1976) reported that relaxin was secreted episodically in humans. They also detected a 24-h rhythm in relaxin secretion. If relaxin is secreted episodically, frequent blood sampling is necessary for estimation of relaxin secretion. There are two radioimmunoassays which measure immunoreactive relaxin in humans. One was developed by Bryant (1972), and the other was developed by Sherwood et al. (1975) and modified by O'Bryne \& Steinetz (1976). The two methods gave different results for circulating relaxin concentrations. Relaxin was readily detected in blood of men and nonpregnant women by the former assay (Bryant et al., 1976), but was almost undetectable by the latter assay (O'Bryne et al., 1978; Quagliarello et al., 1980; Thomas et al., 1980). Furthermore, the specificity of the former assay is questionable (Schwabe et al., 1978). However, a 24-h secretory pattern of relaxin has not heretofore been evaluated in humans using the radioimmunoassay of O'Bryne \& Steinetz (1976). We have therefore tried to measure relaxin concentrations in nonpregnant and pregnant women to determine whether there is a $24-\mathrm{h}$ secretory pattern.

\section{Materials and Methods}

Three normal cyclic women aged 23, 25 and 28 years, studied during the mid-luteal phase, and 2 normal pregnant women (first trimester) aged 25 and 29 years were the subjects of this study. All were healthy, none had ever received hormone therapy or was taking drugs. All subjects slept in the same room for at least 2 days before examination. Blood samples were obtained from each subject every $30 \mathrm{~min}$ through an indwelling catheter placed in a wrist vein. During this study, normal feeding was continued at $08: 00,12: 00$ and 17:00 h, although activity was restricted to the patient's room. Lights were turned off between 21:00 and 06:00 h. Relaxin was measured by radioimmunoassay with ${ }^{125} \mathrm{I}-\mathrm{labelled}$ polytyrosyl relaxin and rabbit antiporcine relaxin serum R6, as previously described (Seki et al., 1986). The sensitivity of the assay was $200 \mathrm{pg} / \mathrm{ml}$. The intra- and inter-assay coefficients of variation were 6.6 and $9 \cdot 3 \%$, respectively.

\section{Results}

Immunoreactive relaxin was undetectable in all serum samples obtained from the 3 nonpregnant women. Relaxin was detected in all serum samples obtained from the 2 pregnant women. The mean ( \pm s.d.) 24 -h relaxin concentrations in these 2 pregnant women were $0.65 \pm 0.07$ and $0.86 \pm 0.04 \mathrm{ng} / \mathrm{ml}$, respectively. Neither episodic secretion of relaxin nor a $24-\mathrm{h}$ rhythm in relaxin secretion was discernible in these women (Fig. 1). 


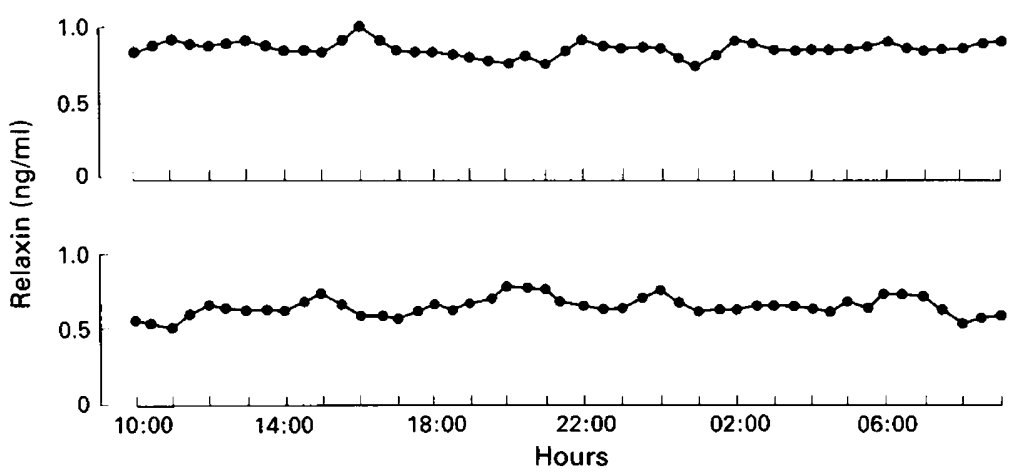

Fig. 1. The serum relaxin immunoactivity of samples collected every $30 \mathrm{~min}$ from 2 pregnant women during the first trimester.

\section{Discussion}

Relaxin was detectable in serum samples of pregnant women, but not in those of nonpregnant women. This is in agreement with the results of previous studies in which radioimmunoassays for relaxin similar to our radioimmunoassays were used (O'Bryne et al., 1978; Quagliarello et al., 1980; Thomas et al., 1980), but not with the result of Bryant et al. (1976). In contrast to the result of Bryant et al. (1976), neither episodic secretion of relaxin nor a $24-\mathrm{h}$ rhythm in relaxin secretion was detected in sera from the pregnant women in this study. The radioimmunoassay of Bryant (1972) was based on porcine relaxin (NIH-R-P1), subsequently recognized to have only about $15 \%$ activity with respect to relaxin (Schwabe et al., 1978). The radioimmunoassay of Sherwood et al. (1975) was based on purified porcine relaxin prepared by the then new method of Sherwood \& O'Bryne (1974). Purified relaxin was not available until 1974. This could explain the differences between the result of Bryant et al. (1976) and ours. If relaxin is not secreted episodically, then repeated short-interval blood sampling is not necessary for estimation of relaxin secretion. However, there is a precedence in the relaxin field for an homologous radioimmunoassay giving a different pattern of results than a heterologous radioimmunoassay. Diurnal rhythms in relaxin secretion have been shown in late pregnancy in the rat and sow by homologous radioimmunoassays (Sherwood et al., 1981, 1983). It may be premature to reach any definite conclusion as to the secretory pattern of relaxin in women, until an homologous radioimmunoassay for human relaxin is established. Previous studies using the R6-polytrosyl radioimmunoassay system have indicated that the corpus luteum of pregnancy is the main source of circulating relaxin in normal pregnancy (Weiss et al., 1976). Therefore, considering the present findings, it seems unlikely that the corpus luteum of pregnancy has its own rhythmicity or is under any rhythmic stimulation to secret relaxin.

We thank Dr W. M. O'Bryne, Ciba-Geigy Corporation, U.S.A., for the generous gift of polytryosyl-relaxin and rabbit antiporcine relaxin serum $\mathbf{R} 6$.

\section{References}

Bryant, G.D. (1972) The detection of relaxin in porcine, ovine and human plasma by radioimmunoassay. Endocrinology 91, 1113-1117.

Bryant, G.D., Sassin, J.F., Weitzman, E.D., Kapen, S.S.
\& Frantz, A. (1976) Relaxin immunoactivity in human plasma during a $24-$ hr period. $J$. Reprod. Fert. 48, 389-392.

O'Bryne, E.M. \& Steinetz, B.G. (1976) Radioimmuno- 
assay (RIA) of relaxin in sera of various species using an antiserum to porcine relaxin. Proc. Soc. exp. Biol. Med. 152, 272-276.

O'Bryne, E.M., Carriere, B.T., Sorensen, I., Segaloff, A., Schwabe, C. \& Steinetz, B.G. (1978) Plasma immunoreactive relaxin levels in pregnant and nonpregnant women. J. clin. Endocr. Metab. 47, 1106-1110.

Quagliarello, J., Goldsmith, L., Steinetz, B.G., Lustig, D.D. \& Weiss, G. (1980) Induction of relaxin secretion in nonpregnant women by human chorionic gonadotrophin. J. clin. Endocr. Metab. 51, 74-77.

Schwabe, C., Steinetz, B., Weiss, G., Segaloff, A., McDonald, J.K., O'Bryne, E., Hochman, J., Carriere, B. \& Goldsmith, L. (1978) Relaxin. Recent Prog. Horm. Res. 34, 123-199.

Seki, K., Uesato, T., Tabei, T. \& Kato, K. (1986) Serum relaxin in patients with hydatidiform mole. Obstet. Gynecol. 67, 381-383.

Sherwood, O.D. \& O'Bryne, E.M. (1974) Purification and characterization of porcine relaxin. Archs Biochem. Biophys. 160, 185-196.

Sherwood, O.D., Rosenterter, K.R. \& Birkhimer, M.L. (1975). Development of a radioimmunoassay for porcine relaxin using ${ }^{125} \mathrm{I}$-labelled polytyrosyl-relaxin. Endocrinology 96, 1106-1113.
Sherwood, O.D., Nara, B.S., Welk, F.A., First, N.L. \& Rutherford, J.E. (1981) Relaxin levels in the maternal plasma of pigs before, during, and after parturition and before, during, and after suckling. Biol. Reprod. 25, 65-71.

Sherwood, O.D., Downing, S.J., Golos, T.G., Gordon, W.L. \& Tarbell, M.K. (1983) Influence of light-dark cycle on antepartum serum relaxin and progesterone immunoactivity levels and on birth in the rat. Endocrinology 113, 997-1003.

Thomas, K., Loumaye, E. \& Ferin, J. (1980) Relaxin in nonpregnant women during ovarian stimulation. Gynecol. Obstet. Invest. 11, 75-80.

Weiss, G., O'Bryne, E.M. \& Steinetz, B.G. (1976) Relaxin: a product of the corpus luteum of pregnancy. Science, N.Y. 194, 948-949.

Received 23 April 1986 